\title{
Optimization and Validation of Thermal Desorption Gas Chromatography-Mass Spectrometry for the Determination of Polycyclic Aromatic Hydrocarbons in Ambient Air
}

\author{
Iñaki Elorduy $\mathbb{i}^{D}$, Nieves Durana, José Antonio García, María Carmen Gómez, \\ and Lucio Alonso \\ Chemical and Environmental Engineering Department, School of Engineering, University of the Basque Country, \\ Alameda de Urquijo s/n, 48013 Bilbao, Spain \\ Correspondence should be addressed to Iñaki Elorduy; inaki.elorduy@ehu.eus
}

Received 21 December 2017; Revised 27 March 2018; Accepted 11 April 2018; Published 2 May 2018

Academic Editor: Verónica Pino

Copyright (c) 2018 Iñaki Elorduy et al. This is an open access article distributed under the Creative Commons Attribution License, which permits unrestricted use, distribution, and reproduction in any medium, provided the original work is properly cited.

\begin{abstract}
Thermal desorption (TD) coupled with gas chromatography/mass spectrometry (TD-GC/MS) is a simple alternative that overcomes the main drawbacks of the solvent extraction-based method: long extraction times, high sample manipulation, and large amounts of solvent waste. This work describes the optimization of TD-GC/MS for the measurement of airborne polycyclic aromatic hydrocarbons (PAHs) in particulate phase. The performance of the method was tested by Standard Reference Material (SRM) 1649b urban dust and compared with the conventional method (Soxhlet extraction-GC/MS), showing a better recovery (mean of 97\%), precision (mean of $12 \%$ ), and accuracy $( \pm 25 \%)$ for the determination of 14 EPA PAHs. Furthermore, other 15 nonpriority PAHs were identified and quantified using their relative response factors (RRFs). Finally, the proposed method was successfully applied for the quantification of PAHs in real $8 \mathrm{~h}$-samples $\left(\mathrm{PM}_{10}\right)$, demonstrating its capability for determination of these compounds in short-term monitoring.
\end{abstract}

\section{Introduction}

Polycyclic aromatic hydrocarbons (PAHs) are a class of persistent organic pollutants (POPs) comprising hundreds of individual substances. These compounds contain two or more fused aromatic rings (made up of carbon and hydrogen atoms) in linear, angular, or cluster arrangements [1]. They are semivolatile organic compounds (SVOC); thus, they are present in the atmosphere in both the gas and the particulate phases as well as dissolved or suspended in precipitation (fog or rain) [2].

PAHs are as by-products of incomplete combustion processes of organic matter [3], and primarily emitted from anthropogenic sources [4], being the mobile and major sources in urban areas $[5,6]$. Their harmful health effects and persistence pose an environmental concern. Thus, these compounds were among the first atmospheric pollutants identified as suspected carcinogens [7]. Moreover, PAHs belong to the group of POPs included in the list of 16 POPs specified by the UNECE Convention on Long-range Transboundary Air Pollution
Protocol on Persistent Organic Pollutants [8, 9]. Due to these features, the United States Environmental Protection Agency (US-EPA) has listed 16 of them as priority pollutants (16 EPA PAHs) [10]. The most toxic PAHs (5 and 6 rings) are linked to the particulate matter $[11,12]$. Accordingly, many air pollution studies have been focused on PAHs bound to particulate matter, particularly $\mathrm{PM}_{10}$ and $\mathrm{PM}_{2.5}$ in order to assess their concentration, distribution, and sources.

Air monitoring for PAHs in urban areas is an important issue because the risk associated with human exposure is higher considering the population density $[13,14]$. However, $\mathrm{PAH}$ data in urban air show large spatial and temporal uncertainties because of the complex sampling and analytical procedures required.

Sampling of particulate PAHs is mostly done by the collection of them on a filter (quartz or glass fiber), using high- or low-volume samplers [15-17]. Once the PAHs have been collected, they have to be extracted for the final determination. The extraction of PAHs from multiple matrices 
is a difficult step. PAHs are found in the environment in very low concentrations; consequently, an effective extraction method, able to quantitatively separate the analytes from the matrix, is required. The widely used method is solvent desorption of sampling media (Soxhlet extraction, accelerated solvent extraction, microwave-assisted extraction, and ultrasonic-assisted extraction) followed by analysis of the compounds of interest by GC-MS (gas chromatography coupled to mass chromatography) or high-performance liquid chromatography coupled with florescence detection (HPLC-FLD) [18, 19], where the detection methods allow cutting most of analytical interferences.

The use of toxic organic solvents in the solvent-based extraction methods causes added difficulties with sample handling and generates large amounts of solvent waste, which is costly and can generate additional environmental problems. Furthermore, the sensitivity of the current analytical procedures limits time resolution of measurements; thus, most of the urban pollution studies rarely achieved temporal resolution measurements better than $24 \mathrm{~h}$. Since the PAH composition of aerosols can vary according to the diurnal changes in the sources, meteorological conditions and atmospheric reactivity [20], the time resolution of $24 \mathrm{~h}$ seems not sufficient to comprehend their variability, fate, and behavior in the atmosphere [21]. For these reasons, the development of simpler and sensitive methods or the improvement of the existing ones is of great interest, for the detection, determination, and monitoring of PAHs.

In recent years, alternative analytical procedures for PAHs based on the use of solvent-free extraction methods have been studied $[22,23]$. Thermal desorption (TD) involves heating sample materials or sorbents in a flow of inert carrier gas, so that retained organic volatiles and semivolatiles are released and transferred or injected into the analytical system (e.g., into the carrier gas stream of the GC column).

The power and potential of TD allow configuring the technique in multiple adsorption-desorption stages, thus enhancing the concentration of the compounds of interest and detection limits. This higher sensitivity may provide shorter sampling times or lower sampling volumes. Another benefit of $\mathrm{TD}$ is that it is often possible to quantitatively retain target compounds during one or more of the trapping stages, while unwanted, for example, water and/or permanent gases, is selectively purged to vent. This avoids the entrance of unwanted compounds into the analytical system that could generate interferences during the analysis and/or damage to the equipment.

This work has tested and optimized different TD-GC/MS operation conditions in order to develop the best method that is able to sample and analyze airborne PAHs in particulate phase. The TD-GC/MS method was later validated by using a Standard Reference Material (SRM) 1649b urban dust and comparing with the conventional method based on solvent extraction (Soxhlet extraction-GC/MS). Moreover, the method was applied to measure PAH levels of $8 \mathrm{~h} \mathrm{PM}_{10}$ samples in ambient air.

\section{Materials and Methods}

2.1. Reagents and Materials. A liquid certificated mixture of 16 EPA PAHs $\left(2000 \mu \mathrm{g} \cdot \mathrm{mL}^{-1}\right.$, SV Calibration Mix 5, Restek Corporation, USA) and a liquid deuterated mixture
(200 $\mu \mathrm{g} \cdot \mathrm{mL}^{-1}$, predeuterated internal standard PAH Mixture 6, Chiron AS, Norway) were used during the study. In Soxhlet extraction, decafluorobiphenyl, $4,4^{\prime}$-dibromooctafluorobiphenyl, $4,4^{\prime}$-dibromobiphenyl. (Restek, $2000 \mu \mathrm{g} \cdot \mathrm{mL}^{-1}$ ), and indeno [1,2,3-cd]pyrene-d12 (Chiron, $100 \mu \mathrm{g} \cdot \mathrm{mL}^{-1}$ ) were used as recovery standard for the assessment of extraction efficiency. Solutions were prepared by appropriate dilution in methanol, HPLC grade (99.9\%, Lab-Scan Analytical Sciences, Poland).

The method was validated using the Standard Reference Material (SRM) 1649b urban dust, obtained from the National Institute of Standards and Technology (NIST, Gaithersburg, MD, USA).

2.2. TD-GC/MS Method. Sampling tubes (stainless steel tube of $5 \mathrm{~mm}$ outer diameter $\times 90 \mathrm{~mm}$ length) packed with filter were analyzed by using TD-GC/MS. The 16 EPA PAHs and deuterated PAHs were spiked on two one-eighth parts of a $47 \mathrm{~mm}$ quartz fiber filter (Whatman International Ltd., UK). These portions, suitably folded, were introduced into the sampling tubes.

Prior to use, the packed sampling tubes were conditioned by thermal cleaning under a helium flow rate of $100 \mathrm{~mL} \cdot \mathrm{min}^{-1}$ at $350^{\circ} \mathrm{C}$ for $30 \mathrm{~min}$.

The NIST Standard Reference Material 1649b was handled in a similar way. Samples of the urban dust $(10 \mathrm{mg})$ were weighed and placed on a one-eighth section of a $47 \mathrm{~mm}$ quartz fiber filter which was rolled and put into the sampling tube. Silanized glass wool (Supelco Inc., Bellefonte, USA) was introduced at the end and at the head of the desorption tubes in order to prevent system contamination.

Prior to use, filters and glass wool plugs were heated in a muffle furnace at $500^{\circ} \mathrm{C}$ for $24 \mathrm{~h}$ to remove trace organic compounds.

PAHs analysis was carried out using an automatic thermal desorber unit (Turbomatrix 150 ATD, Perkin Elmer S.L., USA) coupled by a fused silica capillary transfer line ( $5 \mathrm{~m}$ length $\times 0.32 \mathrm{~mm}$ I.D.) to a GC/MS detector (Clarus 500, Perkin Elmer S.L., USA). The chromatographic separation of PAHs was conducted on a Meta. X5 (silphenylene phase) capillary column: $30 \mathrm{~m}$ length $\times 0.25 \mathrm{~mm}$ I.D. $\times 0.25 \mathrm{~mm}$ film thickness (Teknokroma, Spain).

The helium gas carrier pressure employed in the GC/MS system was $145 \mathrm{kPa}$, and the column temperature was programmed as follows: initial temperature $100^{\circ} \mathrm{C}$ for $3 \mathrm{~min}$, ramp of $10^{\circ} \mathrm{C} \cdot \mathrm{min}^{-1}$ until $250^{\circ} \mathrm{C}$, ramp of $5^{\circ} \mathrm{C} \cdot \mathrm{min}^{-1}$ until $320^{\circ} \mathrm{C}$, and finally temperature held at $320^{\circ} \mathrm{C}$ for $10 \mathrm{~min}$. The total analysis time was $42 \mathrm{~min}$ per sample. The temperature of both the transfer lines (from TD to GC and from GC to MS) was held at $280^{\circ} \mathrm{C}$, whereas the source temperature was $250^{\circ} \mathrm{C}$. Simultaneous full scan (SCAN) and selective ion monitoring (SIM) modes were used for the identification and quantification of PAHs. Table 1 shows, according to their elution order, the PAHs determined in this study with their quantification ions. Supplementry Figures S1-S3 show the representative SCAN chromatograms of the 16 EPA and deuterated PAHs.

2.3. Soxhlet Extraction-GC/MS Method. Between 300 and $500 \mathrm{mg}$ of the NIST SRM 1649b urban dust was weighted and placed on one-eighth of a $150 \mathrm{~mm}$ prebaked (at $500^{\circ} \mathrm{C}$ 
TABLE 1: Abbreviations and quantification ions of PAHs determined by the TD-GC/MS method.

\begin{tabular}{|c|c|c|}
\hline $\mathrm{PAH}$ & Abbreviation & Ion $(\mathrm{m} / \mathrm{z})$ \\
\hline Naphthalene- $\mathrm{d}_{8}{ }^{\mathrm{b}}$ & Naph- $\mathrm{d}_{8}$ & 136 \\
\hline Naphthalene $\mathrm{e}^{\mathrm{a}}$ & Naph & 128 \\
\hline Biphenyl- $\mathrm{d}_{10}{ }^{\mathrm{b}}$ & Bph-d $\mathrm{d}_{10}$ & 164 \\
\hline Acenaphthylene $^{\mathrm{a}}$ & Acy & 152 \\
\hline Acenaphthene $^{\mathrm{a}}$ & Ace & 154 \\
\hline Fluorene $^{\mathrm{a}}$ & FL & 166 \\
\hline Phenanthrene- $\mathrm{d}_{10}{ }^{\mathrm{b}}$ & Phe- $\mathrm{d}_{10}$ & 188 \\
\hline Phenanthrene $^{\mathrm{a}}$ & Phe & 178 \\
\hline Anthracene $\mathrm{e}^{\mathrm{a}}$ & Ant & 178 \\
\hline Fluoranthen $\mathrm{e}^{\mathrm{a}}$ & $\mathrm{Ft}$ & 202 \\
\hline Pyrene- $d_{10}^{b}$ & Pyr- $\mathrm{d}_{10}$ & 212 \\
\hline Pyrene $^{a^{a}}$ & Pyr & 202 \\
\hline Benzo[ghi]fluoranthene $e^{c}$ & BghiFt & 226 \\
\hline Benzo[c]phenanthrene ${ }^{c}$ & $\mathrm{BcP}$ & 228 \\
\hline Cyclopenta[cd]pyrene $e^{c}$ & $\mathrm{CPP}$ & 226 \\
\hline Benzo[a]anthracene- $d_{12}{ }^{b}$ & $\mathrm{BaA}-\mathrm{d}_{12}$ & 240 \\
\hline Benzo[a]anthracene $\mathrm{a}^{\mathrm{a}}$ & $\mathrm{BaA}$ & 228 \\
\hline Triphenylene $^{c}$ & Triph & 228 \\
\hline Chrysene $^{\mathrm{a}}$ & Chry & 228 \\
\hline Retene $^{c}$ & Ret & 234 \\
\hline Benzo[b]fluoranthene $\mathrm{e}^{\mathrm{a}}$ & $\mathrm{BbFt}$ & 252 \\
\hline Benzo[j]fluoranthene $e^{c}$ & $\mathrm{BjFt}$ & 252 \\
\hline Benzo[k]fluoranthene $\mathrm{e}^{\mathrm{a}}$ & $\mathrm{BkFt}$ & 252 \\
\hline Benzo[a]fluoranthene $e^{c}$ & $\mathrm{BaFt}$ & 252 \\
\hline Benzo[e]pyrene $e^{c}$ & $\mathrm{BeP}$ & 252 \\
\hline Benzo[a]pyrene- $\mathrm{d}_{10}{ }^{\mathrm{b}}$ & $\mathrm{BaP}-\mathrm{d}_{10}$ & 264 \\
\hline Benzo[a]pyrene ${ }^{a}$ & $\mathrm{BaP}$ & 252 \\
\hline Perylene ${ }^{c}$ & Per & 252 \\
\hline Dibenzo[a,j]anthracene $e^{c}$ & DBajA & 278 \\
\hline Indeno $[1,2,3$-cd $]$ pyrene $\mathrm{a}^{\mathrm{a}}$ & IP & 276 \\
\hline Dibenzo[ac]anthracene $e^{c}$ & DBacA & 278 \\
\hline Dibenzo[ah]anthracene $\mathrm{a}^{\mathrm{a}}$ & DBahA & 278 \\
\hline Benzo[b]chrysene ${ }^{c}$ & $\mathrm{BbC}$ & 278 \\
\hline Picene $^{c}$ & Pic & 278 \\
\hline Benzo[ghi]perylene- $\mathrm{d}_{12}{ }^{\mathrm{b}}$ & BghiP- $\mathrm{d}_{12}$ & 288 \\
\hline Benzo[ghi]perylene $\mathrm{a}^{\mathrm{a}}$ & BghiP & 278 \\
\hline Anthanthrene $e^{c}$ & Anthan & 276 \\
\hline Coronene $^{c}$ & Cor & 300 \\
\hline
\end{tabular}

${ }^{a} 16$ EPA PAHs; ${ }^{b}$ deuterated PAHs; ${ }^{c}$ nonpriority PAHs.

for $24 \mathrm{~h}$ ) quartz fiber filter (Whatman International Ltd.). Before folding the filter, it was spiked with the recovery standards.

Soxhlet extraction was performed by using Büchi extraction system B-811 (BÜCHI, Switzerland), an automated system that can be used to perform extraction according to the original Soxhlet principle. The samples were extracted with hexane using the Soxhlet Warm mode. This mode increases the solubility of the analytes, allowing an optimal extraction in 3 hours [24].

After the extraction process, the extracts of $5 \mathrm{~mL}$ were concentrated by a stream of dry nitrogen to a volume less than $0.5 \mathrm{~mL}$. Finally, these extracts were diluted to $1.5 \mathrm{~mL}$ with methanol and spiked with deuterated PAHs.

Two-microliters of aliquots from each extract was injected into the GC/MS with split mode. Table 2 collects the timed events and the oven program used in the GC/MS during the validation of the Soxhlet method.
Also, in this method, the GC/MS used simultaneously the SCAN and SIM mode for the identification and quantification of PAHs.

2.4. Sample Collection. Airborne particulate matter $\left(\mathrm{PM}_{10}\right)$ samples were collected on preheated (at $500^{\circ} \mathrm{C}$ for $24 \mathrm{~h}$ ) quartz fiber filters $(150 \mathrm{~mm}$ diameter, Whatman International Ltd., United Kingdom) using a high-volume sampler (Digitel DHA-80, Digitel Elektronik AG, Switzerland) with a flow rate of $30 \mathrm{~m}^{3} \cdot \mathrm{h}^{-1}$. DHA-80 stores 15 filters stretched in filter holders that are changed automatically at the preset time. DHA-80 has integrated temperature control in the filter storage section; in this way, the used filters can be stored at low temperatures (in this study at $4^{\circ} \mathrm{C}$ ) after sampling.

Collected filters were put into individual Petri dishes, wrapped in aluminum foil, and kept in a $4^{\circ} \mathrm{C}$ freezer until analysis (<15 days) according to ISO 12884:2000 [25].

\section{Results and Discussion}

3.1. Optimization of Thermal Desorption Method. The thermal desorption process can be divided into two main stages: tube and trap desorption. In the first stage, target compounds are thermally desorbed from the sampling tube and transferred to the cold trap, where they are concentrated. After completing the primary desorption, the trapped compounds are released by quick heating of the trap and swept through the heated transfer line to the GC column.

To obtain the best analytical conditions in terms of sensitivity and reproducibility, different parameters in each desorption stage were tested.

For these tests, $1 \mu \mathrm{L}$ of the 16 EPA PAHs solutions of $20 \mathrm{ng} \cdot \mu \mathrm{L}^{-1}$ were spiked in sampling tubes packed with portions of quartz fiber.

3.1.1. Primary Desorption (Tube Desorption). The conditions in the tube oven during this stage are key to guarantee an efficient desorption; thus, parameters such as the temperature, time, and flow in the tube oven were studied to optimize this process.

Different values of desorption temperatures, times, and flows were tested, considering factors such as the packing/sample matrix stability, the lability of the components of interest, and the temperature limitations of the system. Figure 1 shows the area of chromatographic peak for each of the 16 EPA PAHs (in \%) obtained for each test.

The results demonstrated that an increase in the temperature of the oven tube enhances the desorption of particulate PAHs (Figure 1(a)). This improvement was remarkable for high molecular weight PAHs (IP, DBahA, and BghiP). A value of $320^{\circ} \mathrm{C}$ was selected as temperature in the first desorption stage. Regarding the time, the lowest value in the test $(10 \mathrm{~min})$ clearly showed significantly higher areas for most compounds (Figure 1(b)), indicating a more efficient desorption. This value was selected as desorption time in the tube. Finally, higher desorption flows enable better desorption of PAHs (Figure 1(c)). Flows higher than 
TABLE 2: Timed events and oven program used in direct injector mode.

\begin{tabular}{|c|c|c|c|c|c|c|}
\hline \multicolumn{3}{|c|}{ Timed event } & \multicolumn{4}{|c|}{ Oven program } \\
\hline Event & Flow $\left(\mathrm{mL} \cdot \mathrm{min}^{-1}\right)$ & Time (min) & Ramp & Rate $\left({ }^{\circ} \mathrm{C} \cdot \mathrm{min}^{-1}\right)$ & Temperature $\left({ }^{\circ} \mathrm{C}\right)$ & Hold (min) \\
\hline Split & 0 & -0.51 & Initial & 0 & 45 & 1 \\
\hline Split & 50 & 1 & 1 & 20 & 200 & 0 \\
\hline Split & 20 & 5 & 2 & 4 & 320 & 5 \\
\hline
\end{tabular}

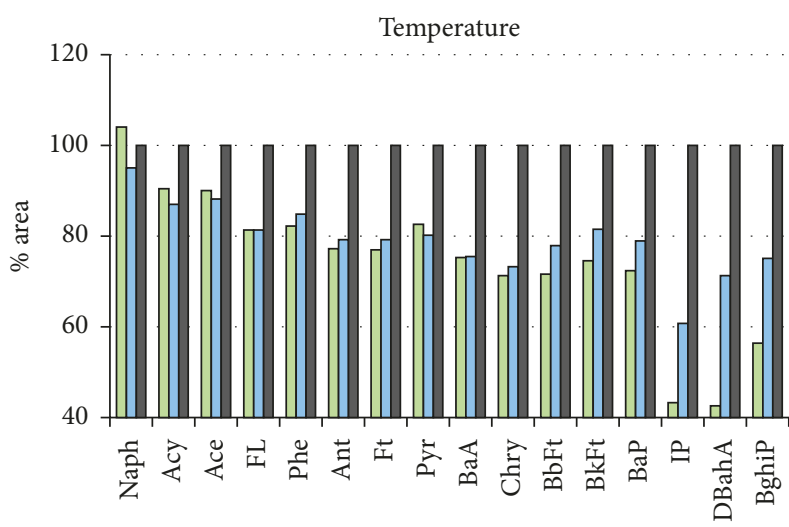

PAHs

$$
\begin{aligned}
& \square 280^{\circ} \mathrm{C} \\
& \square 300^{\circ} \mathrm{C} \\
& \square 320^{\circ} \mathrm{C}
\end{aligned}
$$

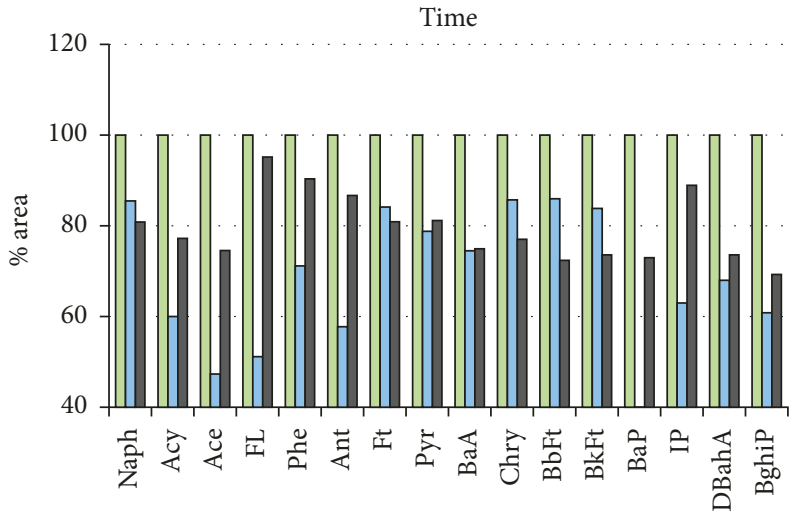

PAHs

$$
\begin{aligned}
& \square 10 \mathrm{~min} \\
& \square 15 \mathrm{~min} \\
& \square 20 \mathrm{~min}
\end{aligned}
$$

(b)

(a)

Flow

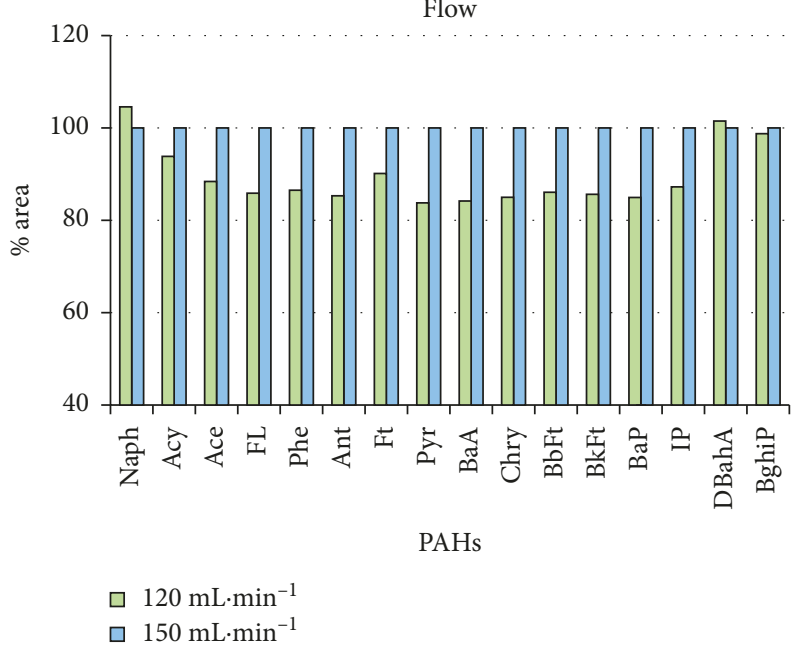

(c)

FIGURE 1: Area (in \%) for each of the 16 EPA PAH obtained in the study of primary desorption conditions (desorption temperature, time, and flow) for sampling tubes $(n=5)$ packed with filter. $\%$ Areas at $280^{\circ} \mathrm{C}$ and $300^{\circ} \mathrm{C}$ are compared to $\%$ areas at $320^{\circ} \mathrm{C}$ chosen as $100 \%($ a). $\%$ Areas at $15 \mathrm{~min}$ and $20 \mathrm{~min}$ are compared to \% areas at $10 \mathrm{~min}$ chosen as $100 \%$ (b). \% Areas at $120 \mathrm{~mL} \cdot \mathrm{min}^{-1}$ is compared to \% areas at $150 \mathrm{~mL} \cdot \mathrm{min}^{-1}$ chosen as $100 \%(\mathrm{c})$.

$150 \mathrm{~mL} \cdot \mathrm{min}^{-1}$ are not recommended, as they can generate problems in maintaining low temperatures in the trap zone during the first desorption stage [26]. Therefore, a flow of $150 \mathrm{~mL} \cdot \mathrm{min}^{-1}$ was selected as the optimal value.

3.1.2. Secondary Desorption (Trap Desorption). To enhance $\mathrm{PAH}$ desorption from the trap (a quartz tube packed with glass wool), its high temperature has to be as high as possible. This temperature depends on the trap packing and equipment stability as well as on the target compounds. In this study, a value of $320^{\circ} \mathrm{C}$ (the value recommended by the manufacturer) was set, while its low temperature (values of $-15,-10$, and $-5^{\circ} \mathrm{C}$ ) and desorption time (values of 4, 6, and $12 \mathrm{~min}$ ) were tested.

The area of chromatographic peak (in \%) for low (2-3 rings: Naph, Ace, Acy, FL, Phe, and Ant), middle (4 rings: Ft, 


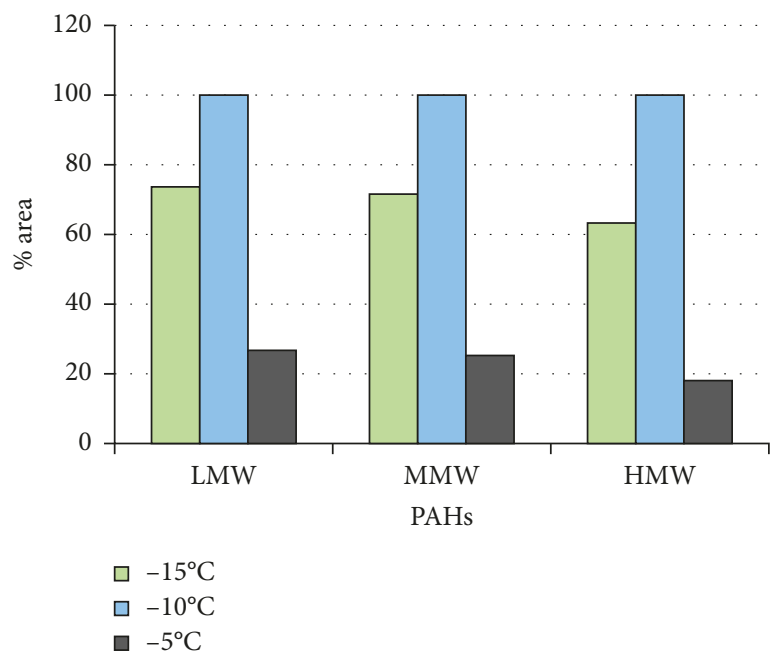

(a)

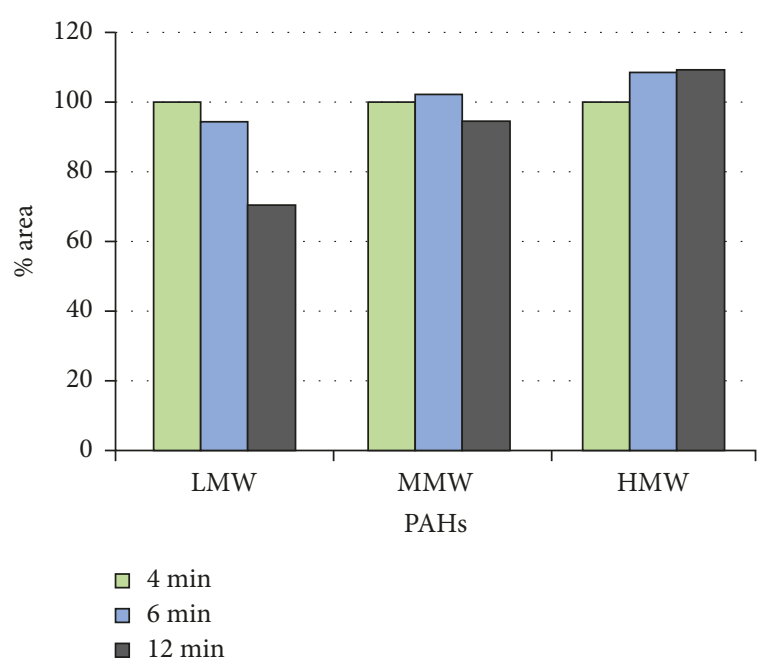

(b)

Figure 2: Area (in \%) for LMW (low molecular weight), MMW (middle molecular weight), and HMW (high molecular weight) PAHs obtained in the study of the low trap temperature (a) and of the trap time (b) for sampling tubes packed with filter $(n=5) . \%$ Areas at $-15^{\circ} \mathrm{C}$ and $-5^{\circ} \mathrm{C}$ are compared to $\%$ areas at $-10^{\circ} \mathrm{C}$ chosen as $100 \%$ (a). \% Areas at 6 min and $12 \mathrm{~min}$ are compared to \% areas at $10 \mathrm{~min}$ chosen as $100 \%(b)$.

Pyr, $\mathrm{BaA}$, and Chry), and high (5-6 rings: $\mathrm{BbFt}, \mathrm{BkFt}, \mathrm{BaP}$, IP, DBahA, and BghiP) molecular weight PAHs obtained for each test are shown in Figure 2.

The temperature in the Peltier trap is a critical parameter in secondary desorption (Figure 2(a)), showing significant changes in the sensitivity for different values. The temperature of $-10^{\circ} \mathrm{C}$ revealed the best results.

In the study of the trap desorption time (Figure 2(b)), the results demonstrated that longer values do not implicate a higher efficiency and consequently a better detection, 6 min showed a better response than 12 . This is especially significant with the lightest PAHs (LMW) which could be affected by the exposure to high temperatures, generating losses. By contrast, the heavier PAHs (MMW and HMW) showed higher concentrations after longer trap desorption times because they could need more time to be completely desorbed. Due to this, a trap duration of $6 \mathrm{~min}$ was selected as this value presented good desorption for 16 target PAHs.

3.1.3. Inlet and Outlet Split Flows. In order to enhance the process of two-stage thermal desorption, a double split mode was used. Therefore, the inlet (split flow as the tube is desorbed) and outlet (split flow as the trap is desorbed) split flows were also tested.

The inlet split flow plays an important role during primary desorption. This maintains a relatively high carrier gas flow through the sample tube, while at the same time establishes a reasonably low flow through the cold trap, aiding the complete removal from the sample tube and analyte retention. The deactivation of the inlet split $\left(0 \mathrm{~mL} \cdot \mathrm{min}^{-1}\right)$ generated a significant improvement in PAH desorption because the complete sample, without purge, arrived at the cold trap. With the increase of inlet split, the sensitivity decreased. Although in this study, an inlet split flow of $0 \mathrm{~mL} \cdot \mathrm{min}^{-1}$ showed the best results; it is recommended to activate this split in order to avoid the presence of unwanted compounds (permanent gases and water) in the trap. These could reduce the trap lifetime and interfere in the analysis. In order to find a compromise between these rules, an intermediate flow $\left(23 \mathrm{~mL} \cdot \mathrm{min}^{-1}\right)$ was considered as the optimal value.

The outlet split flow also plays an important function in the trap desorption: (1) adapting the effluent flow to a capillary column flow, it avoids the system saturation and (2) facilitating the release of the analytes, it guarantees a high enough flow through the trap during desorption. According to the manufacturer, at least $10 \mathrm{~mL} \cdot \mathrm{min}^{-1}$ of outlet split is necessary to minimize the air/water background on a mass spectrometer when atmospheric samples are analysed [26]. In this study, the results obtained for outlet split flows demonstrated that the increase of this parameter reduces the sensitivity of the technique, with losses becoming significant between 10 and $20 \mathrm{~mL} \cdot \mathrm{min}^{-1}$. Therefore, the manufacturer's recommended flow $\left(10 \mathrm{~mL} \cdot \mathrm{min}^{-1}\right)$ was selected as the optimal value.

Finally, Table 3 summaries the optimized values for thermal desorption.

3.2. Desorption Efficiency. Once optimized, the efficiency of two-stage thermal desorption was studied. The efficiency was calculated by the following expression:

$$
E(\%)=\left(\frac{A}{A+A^{*}}\right) \times 100,
$$

where $E$ is the efficiency in \%, $A$ is the peak area of the analyte obtained from desorption of the sampling tube (previously loaded with PAHs), and $A^{*}$ is the peak area of the analyte obtained when the same sampling tube or the trap was desorbed the second time. 
TABle 3: Optimized conditions for thermal desorption system.

\begin{tabular}{|c|c|c|c|}
\hline \multicolumn{2}{|c|}{ Primary desorption } & \multicolumn{2}{|c|}{ Secondary desorption } \\
\hline Parameter & & Parameter & \\
\hline $\begin{array}{c}\text { Tube } \\
\text { temperature }\end{array}$ & $320^{\circ} \mathrm{C}$ & $\begin{array}{l}\text { High trap } \\
\text { temperature }\end{array}$ & $320^{\circ} \mathrm{C}$ \\
\hline Time & $10 \mathrm{~min}$ & $\begin{array}{l}\text { Low trap } \\
\text { temperature }\end{array}$ & $-10^{\circ} \mathrm{C}$ \\
\hline $\begin{array}{c}\text { Desorption } \\
\text { flow }\end{array}$ & $150 \mathrm{~mL} \cdot \mathrm{min}^{-1}$ & Time & $6 \mathrm{~min}$ \\
\hline Inlet split flow & $23 \mathrm{~mL} \cdot \mathrm{min}^{-1}$ & Outlet split flow & $10 \mathrm{~mL} \cdot \mathrm{min}^{-1}$ \\
\hline
\end{tabular}

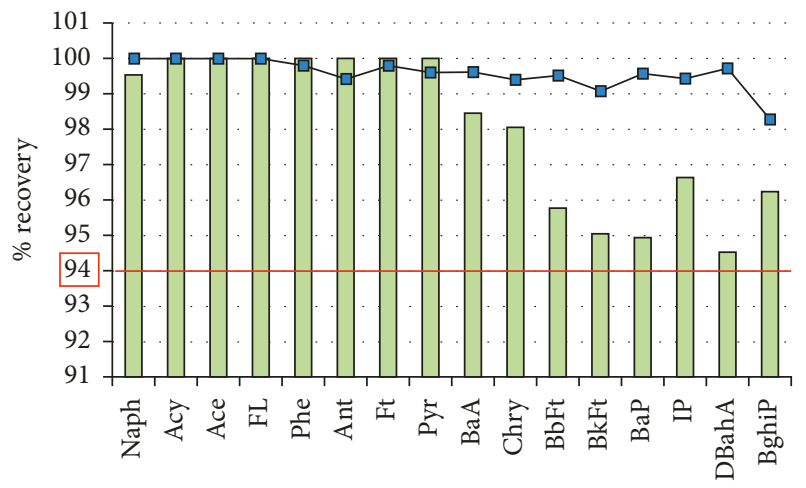

PAHs

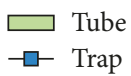

Figure 3: Recovery (in \%) of the 16 EPA PAHs (particulate phase) in each stage of the thermal desorption.

Figure 3 shows the tube and trap efficiencies obtained for each particulate PAH. The technique demonstrated a good efficiency with recoveries of the PAHs in the tube and trap higher than $94 \%$.

3.3. TD-GC/MS Validation and Comparison with Soxhlet$G C / M S$. In order to determine the performance of the method when applied to atmospheric PM samples, this was tested using the Standard Reference Material (SRM) 1649b urban dust.

The accuracy, repeatability, and recovery of the method were calculated by adding known amounts (approximately $10 \mathrm{mg}$ ) of the SRM 1649b to a one-eighth section of blank filters $(n=10)$. Before the analysis, filters were spiked with $1 \mu \mathrm{L}$ of the deuterated $\mathrm{PAH}$ internal standard solution $\left(25 \mathrm{ng} \cdot \mu \mathrm{L}^{-1}\right)$.

Table 4 shows the results obtained for each PAH by using the TD-GC/MS method, comparing the calculated concentration with the certified values.

Although the column used in this study demonstrated a good resolution for the $16 \mathrm{EPA}$ PAHs, the presence of other PAHs in the urban dust can generate coelution problems with the target compounds [27]. Some PAH pairs such as BbFt and DBahA coeluted with the benzo[j]fluoranthene $(\mathrm{BjFt})$ and dibenzo[a,c]anthracene $(\mathrm{DBacA})$, respectively.

The TD-GC/MS method showed good precision with mean RSD values of 12.2. The accuracy of the TD-GC/MS method ranged from $-22.8 \%$ to $25.1 \%$, while the average recovery efficiency was 96.7 . These performance parameters of the TD-GC/MS method accomplish the quality objectives for ambient air PAHs stated by ISO 12884:2000 [25], which establishes a precision of $\pm 25 \%$, an accuracy of $\pm 20 \%$, and a recovery efficiency between 75 and $125 \%$. These requirements are accomplished for most PAH; however, there are some exceptions. The lowest molecular weight PAHs (Naph and Acy), with excessively high recoveries, confirmed the overestimation of these compounds when analyzed by using the TD-GC/MS method. These compounds could suffer losses during the sample preparation due to their high volatility. Besides, the presence of interfering compounds in the SRM and the low concentration of Acy could explain these overestimations. Therefore, this method was not applicable to the Naph and Acy analysis.

In order to demonstrate the efficiency of the TD method as compared with other analytical methods, the conventional method (Soxhlet extraction-GC/MS) was also tested (Table 5). Between 300 and $500 \mathrm{mg}$ of the NIST SRM 1649b urban dust was placed on one-eighth of a $150 \mathrm{~mm}$ prebaked quartz fiber filter, which was spiked with $1 \mu \mathrm{L}$ of a solution $\left(0.5 \mathrm{ng} \cdot \mu \mathrm{L}^{-1}\right)$ of the recovery standards. After the extraction process, the obtained extracts were spiked with $25 \mu \mathrm{L}$ of a deuterated PAH solution $\left(20 \mathrm{ng} \cdot \mu \mathrm{L}^{-1}\right)$.

The results of the Soxhlet extraction-GC/MS method showed a good recovery for 4-, 5-, and 6-ring PAHs with values between 72.8 and $131 \%$; whereas the lightest PAHs (2and 3-ring PAHs), except Phe, showed low recovery $(<70 \%)$. The loss of these analytes during the extraction process in the Soxhlet Warm mode could be the main reason for these low recoveries. In the case of DBahA, although its coelution with DBacA was considered, its recovery continued to be high $(>200 \%)$. This indicates an overestimation in the determination of this compound by the Soxhlet process. Regarding precision and accuracy, the Soxhlet extraction-GC/MS showed worse results, with an average precision of 34.9 and values of accuracy out of the limits $\pm 20 \%$ for some PAHs.

Comparing both methods, the TD-CG/MS method demonstrated a better performance (good recovery, precision, and accuracy) for the determination of PAHs (except for Naph and Acy). By contrast, the manipulation of the samples in the Soxhlet process meant losses of the light PAHs (2- and 3-ring) and an overestimation of some PAHs, especially of the DBahA.

Regarding the detection limits, the average instrument detection limit (IDL) of the TD-GC/MS method was $0.04 \mathrm{ng}$ and the average method detection limit (MDL), assuming a total sample volume $240 \mathrm{~m}^{3}\left(30 \mathrm{~m}^{3} \cdot \mathrm{h}^{-1}\right.$ for $\left.8 \mathrm{~h}\right)$, was $2.89 \times 10^{-3} \mathrm{ng} \cdot \mathrm{m}^{-3}$ [28].

3.4. Extension of the Scope to Other PAHs. Although most environmental studies are focused on the analysis of $16 \mathrm{PAH}$ listed by US-EPA, it could be interesting to determine other PAHs in order to have a better characterization of these compounds in terms of toxicity and sources. For this reason, besides the $16 \mathrm{EPA}$ PAHs, other $15 \mathrm{PAHs}$ were determinated by using TD-GC/MS. Table 1 shows, according to their 
TABLE 4: TD-GC/MS method validation parameters for the 16 EPA PAHs in NIST SRM 1649b urban dust $(n=10)$.

\begin{tabular}{|c|c|c|c|c|c|}
\hline $\mathrm{PAH}$ & 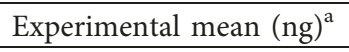 & NIST-certified value (ng) ${ }^{\mathrm{a}}$ & RSD (\%) & Recovery (\%) & $\operatorname{Accuracy}^{\mathrm{b}}(\%)$ \\
\hline Naph & $3694 \pm 1082$ & $26.8 \pm 3.0$ & 46.3 & 13809 & 13709 \\
\hline Acy & $6.97 \pm 0.61$ & $1.99 \pm 0.24$ & 13.9 & 351 & 251 \\
\hline Ace & $1.57 \pm 0.19$ & $2.03 \pm 0.41$ & 19.5 & 77.3 & -22.8 \\
\hline FL & $2.06 \pm 0.21$ & $2.29 \pm 0.67$ & 16.4 & 89.9 & -10.1 \\
\hline Phe & $42.7 \pm 3.3$ & $45.3 \pm 0.2$ & 12.0 & 94.3 & -5.70 \\
\hline Ant & $12.6 \pm 0.8$ & $10.1 \pm 0.2$ & 9.82 & 125 & 25.1 \\
\hline Ft & $59.6 \pm 3.2$ & $67.9 \pm 0.4$ & 8.56 & 87.7 & -12.3 \\
\hline Pyr & $51.8 \pm 2.8$ & $51.2 \pm 1.4$ & 8.56 & 101 & 1.01 \\
\hline $\mathrm{BaA}$ & $19.3 \pm 1.1$ & $21.7 \pm 0.5$ & 8.70 & 88.7 & -11.3 \\
\hline Chry & $26.2 \pm 1.3$ & $31.3 \pm 0.3$ & 7.95 & 83.5 & -16.5 \\
\hline $\mathrm{BbFt}+\mathrm{BjFt}$ & $75.0 \pm 6.2$ & $81.3 \pm 2.3$ & 13.0 & 92.2 & -7.79 \\
\hline $\mathrm{BkFt}$ & $16.1 \pm 1.4$ & $17.5 \pm 0.5$ & 13.4 & 91.9 & -8.15 \\
\hline $\mathrm{BaP}$ & $20.4 \pm 1.5$ & $25.4 \pm 1.2$ & 11.5 & 80.2 & -19.8 \\
\hline IP & $35.5 \pm 1.9$ & $29.7 \pm 1.7$ & 8.63 & 119 & 19.3 \\
\hline $\mathrm{DBahA}+\mathrm{DBacA}$ & $6.35 \pm 0.93$ & $6.02 \pm 0.11$ & 23.1 & 105 & 5.42 \\
\hline BghiP & $37.2 \pm 2.2$ & $40.8 \pm 0.4$ & 9.31 & 91.1 & -8.90 \\
\hline Average $^{c}$ & - & - & 12.2 & 96.7 & $|12.4|$ \\
\hline
\end{tabular}

${ }^{a}$ Expanded uncertainty about the mean, with coverage factor, $k=2$; ${ }^{b}$ accuracy $=($ experimental value - certified value $) \times 100 /$ certified value; ${ }^{c}$ except Naph and Acy.

TABLE 5: Soxhlet extraction-GC/MS method validation parameters for the 16 EPA PAHs in SRM 1649b $(n=7)$.

\begin{tabular}{|c|c|c|c|c|c|}
\hline $\mathrm{PAH}$ & Experimental mean $(\mathrm{ng})^{\mathrm{a}}$ & NIST-certified value (ng) ${ }^{\mathrm{a}}$ & RSD (\%) & Recovery (\%) & Accuracy $^{\mathrm{b}}(\%)$ \\
\hline $\mathrm{Naph}$ & $67.3 \pm 18.6$ & $391 \pm 35$ & 33.8 & 17.2 & -82.8 \\
\hline Acy & $20.2 \pm 5.9$ & $79.9 \pm 9.5$ & 35.9 & 25.2 & -74.8 \\
\hline Ace & $25.0 \pm 5.4$ & $81.6 \pm 16.5$ & 26.5 & 30.7 & -69.4 \\
\hline FL & $32.6 \pm 9.2$ & $92.3 \pm 14.4$ & 34.5 & 35.3 & -64.7 \\
\hline Phe & $1215 \pm 331$ & $1668 \pm 24$ & 33.4 & 72.8 & -27.2 \\
\hline Ant & $104 \pm 25$ & $169 \pm 1$ & 32.5 & 61.8 & -38.2 \\
\hline $\mathrm{Ft}$ & $2392 \pm 559$ & $2573 \pm 32$ & 31.0 & 93.0 & -7.05 \\
\hline Pyr & $1914 \pm 398$ & $2054 \pm 57$ & 27.6 & 93.2 & -6.79 \\
\hline $\mathrm{BaA}$ & $808 \pm 148$ & $870 \pm 20$ & 24.3 & 92.9 & -7.13 \\
\hline Chry & $1632 \pm 464$ & $1256 \pm 11$ & 37.6 & 129 & 29.9 \\
\hline $\mathrm{BbFt}+\mathrm{BjFt}$ & $3144 \pm 800$ & $3260 \pm 91$ & 33.7 & 96.4 & -3.58 \\
\hline $\mathrm{BkFt}$ & $921 \pm 319$ & $702 \pm 20$ & 45.9 & 131 & 31.3 \\
\hline $\mathrm{BaP}$ & $1019 \pm 271$ & $1018 \pm 98$ & 35.2 & 100 & 0.07 \\
\hline IP & $1109 \pm 296$ & $1192 \pm 65$ & 35.4 & 93.1 & -6.89 \\
\hline $\mathrm{DBahA}+\mathrm{DBacA}$ & $507 \pm 176$ & $241 \pm 4$ & 45.9 & 363 & 263 \\
\hline BghiP & $2143 \pm 580$ & $1777 \pm 32$ & 35.8 & 120 & 20.6 \\
\hline Average $^{c}$ & - & - & 34.9 & 120 & $|36.8|$ \\
\hline
\end{tabular}

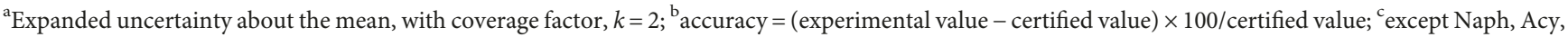
Ace, and FL.

elution order, the 16 EPA PAHs, the deuterated PAHs, and the 15 nonpriority PAHs.

Because SRM 1649b contains other compounds besides the 16 EPA PAHs, it was used to identify 15 nonpriority PAHs and to quantify them by relative response factors (RRFs). Supplementry Figures S4-S7 show the SIM chromatograms of the target PAHs (16 EPA PAHs + 15 PAHs) obtained in the analysis of SRM 1649b. For quantification, the RRFs for each nonpriority PAH were calculated by the following equation:

$$
\mathrm{RRF}_{\mathrm{PAH}}=\frac{A_{\mathrm{PAH}} \cdot C_{\text {ref.PAH }}}{A_{\text {ref.PAH }} \cdot C_{\mathrm{PAH}}},
$$

where $A_{\mathrm{PAH}}$ is the peak area of nonpriority PAH, $A_{\text {ref.PAH }}$ is the peak area of reference $\mathrm{PAH}$ compound, $\mathrm{C}_{\mathrm{PAH}}$ is the nonpriority PAH concentration in the NIST dust, and $C_{\text {ref.PAH }}$ is the reference PAH concentration in the NIST dust.

Reference PAHs were selected according to the following criterion: the nearest of the 16 EPA PAHs to each new one, which provides the least variation in the RRF. Table 6 collects the reference PAHs, RRFs, and the relative standard deviations (RSDs) for each nonpriority PAH.

The nonpriority PAHs showed a range of RRFs between 0.31 and 4.74 , with RSD of less than $15 \%$ for most compounds. In the case of Ret, the low chemical similarity between this compound and its reference $\mathrm{PAH}(\mathrm{BaA})$ could explain the poor precision in the determination of its RRF (>20\%).

3.5. Application to Real Samples. After validation, the method described in this study was applied to extract and analyze samples 
TABLE 6: Reference PAH, RRFs, and the relative standard deviations (RSDs) for each nonpriority PAH.

\begin{tabular}{lccc}
\hline Nonpriority PAH & Reference PAH & RRF & RSD (\%) \\
\hline BghiFt & $\mathrm{BaA}$ & 1.29 & 0.76 \\
BcP & $\mathrm{BaA}$ & 0.31 & 13.2 \\
CPP & $\mathrm{BaA}$ & 0.69 & 15.1 \\
Triph & $\mathrm{BaA}$ & 1.13 & 16.1 \\
Ret & $\mathrm{BaA}$ & 0.99 & 25.6 \\
BaFt & $\mathrm{BkFt}$ & 1.31 & 11.3 \\
BeP & $\mathrm{BaP}$ & 0.94 & 4.10 \\
Per & $\mathrm{BaP}$ & 4.74 & 4.05 \\
DBajA & $\mathrm{IP}$ & 1.08 & 4.49 \\
BbC & $\mathrm{IP}$ & 0.64 & 6.16 \\
Pic & $\mathrm{IP}$ & 0.40 & 10.2 \\
Anthan & $\mathrm{BghiP}$ & 0.54 & 8.54 \\
Cor & BghiP & 15.8 \\
\hline
\end{tabular}

TABLE 7: Descriptive statistics of the individual particle-bound PAH concentrations measured in the city of Bilbao.

\begin{tabular}{|c|c|c|c|c|c|c|c|}
\hline PAH & $\mathrm{N}$ & Average $\left(\mathrm{ng} \cdot \mathrm{m}^{-3}\right)$ & $\mathrm{SD}\left(\mathrm{ng} \cdot \mathrm{m}^{-3}\right)$ & Min. $\left(\right.$ ng. $\left.\mathrm{m}^{-3}\right)$ & Max. $\left(\mathrm{ng} \cdot \mathrm{m}^{-3}\right)$ & 5 th percentile $\left(\mathrm{ng} \cdot \mathrm{m}^{-3}\right)$ & $\begin{array}{l}\text { 95th percentile } \\
\left(\text { ng. } \mathrm{m}^{-3}\right)\end{array}$ \\
\hline Ace* & 180 & 0.22 & 0.27 & $4.00 \times 10^{-3}$ & 1.69 & 0.02 & 0.85 \\
\hline $\mathrm{FL}^{*}$ & 182 & 0.08 & 0.07 & 0.01 & 0.61 & 0.02 & 0.22 \\
\hline $\mathrm{Phe}^{*}$ & 182 & 0.17 & 0.12 & 0.03 & 0.80 & 0.05 & 0.41 \\
\hline Ant* & 182 & 0.04 & 0.05 & $4.00 \times 10^{-3}$ & 0.48 & 0.01 & 0.14 \\
\hline $\mathrm{Ft}^{*}$ & 182 & 0.26 & 0.22 & 0.03 & 1.38 & 0.06 & 0.73 \\
\hline Pyr* & 182 & 0.27 & 0.23 & 0.02 & 1.48 & 0.05 & 0.73 \\
\hline BghiFt & 118 & 0.20 & 0.19 & 0.01 & 0.87 & 0.03 & 0.60 \\
\hline $\mathrm{BcP}$ & 181 & 0.06 & 0.06 & $4.00 \times 10^{-3}$ & 0.40 & $8.00 \times 10^{-3}$ & 0.20 \\
\hline СРP & 73 & 0.07 & 0.16 & $3.00 \times 10^{-3}$ & 0.95 & $5.00 \times 10^{-3}$ & 0.48 \\
\hline $\mathrm{BaA}^{*}$ & 182 & 0.16 & 0.22 & 0.01 & 1.45 & 0.02 & 0.62 \\
\hline Triph & 164 & 0.14 & 0.13 & 0.02 & 0.74 & 0.03 & 0.43 \\
\hline Chry* & 182 & 0.22 & 0.24 & 0.03 & 1.35 & 0.04 & 0.81 \\
\hline $\mathrm{BbFt}^{*}+\mathrm{BjFt}$ & 175 & 0.50 & 0.76 & 0.03 & 5.98 & 0.06 & 2.08 \\
\hline $\mathrm{BkFt}^{*}$ & 174 & 0.18 & 0.23 & 0.01 & 1.41 & 0.03 & 0.64 \\
\hline $\mathrm{BaFt}$ & 141 & 0.05 & 0.07 & $3.00 \times 10^{-3}$ & 0.39 & $4.00 \times 10^{-3}$ & 0.21 \\
\hline $\mathrm{BeP}$ & 169 & 0.26 & 0.32 & 0.01 & 1.83 & 0.03 & 0.93 \\
\hline $\mathrm{BaP}^{*}$ & 170 & 0.16 & 0.20 & 0.01 & 1.16 & 0.02 & 0.70 \\
\hline Per & 159 & 0.03 & 0.04 & $2.00 \times 10^{-3}$ & 0.19 & $4.00 \times 10^{-3}$ & 0.14 \\
\hline DBajA & 111 & 0.01 & 0.01 & $2.00 \times 10^{-4}$ & 0.06 & $4.00 \times 10^{-4}$ & 0.03 \\
\hline $\mathrm{IP}^{*}$ & 161 & 0.17 & 0.24 & $1.00 \times 10^{-3}$ & 1.52 & 0.01 & 0.70 \\
\hline $\mathrm{DBahA}^{*}+\mathrm{DBacA}$ & 143 & 0.05 & 0.06 & $3.00 \times 10^{-4}$ & 0.38 & $3.00 \times 10^{-3}$ & 0.19 \\
\hline $\mathrm{BbC}$ & 62 & 0.01 & 0.01 & $2.00 \times 10^{-3}$ & 0.05 & $3.00 \times 10^{-3}$ & 0.04 \\
\hline $\mathrm{Pic}$ & 63 & 0.03 & 0.04 & $3.00 \times 10^{-3}$ & 0.24 & $4.00 \times 10^{-3}$ & 0.13 \\
\hline BghiP* & 174 & 0.20 & 0.19 & 0.01 & 1.03 & 0.04 & 0.66 \\
\hline Anthan & 48 & 0.03 & 0.05 & $3.00 \times 10^{-3}$ & 0.26 & $3.00 \times 10^{-3}$ & 0.15 \\
\hline Cor & 53 & 0.10 & 0.12 & 0.01 & 0.44 & 0.02 & 0.36 \\
\hline
\end{tabular}

*PAH listed as priority pollutant by US-EPA.

collected in the city of Bilbao, Spain (longitude $2^{\circ} 56^{\prime} 56.24^{\prime \prime} \mathrm{W}$, latitude $3^{\circ} 15^{\prime} 44.86^{\prime \prime} \mathrm{N}$ ). Bilbao city is the most populated area in the Basque Country and the tenth largest in Spain (approximately 350,000 in the city and 1 million inhabitants in the metropolitan area). In this urban area, local traffic and stationary emissions from the surrounding industries are considered as the major sources of atmospheric pollutants [28].

During seven consecutive days per month, eight-hour $\mathrm{PM}_{10}$ samples were collected at a flow rate of $30 \mathrm{~m}^{3} \cdot \mathrm{h}^{-1}$.

A total of $182 \mathrm{PM}_{10}$ samples were collected over 9 months (between July 2013 and June 2014). Each sample was randomly cut into 8 portions of $1 \mathrm{~cm}^{2}$ and introduced into the sampling tube and analyzed using the optimized method.
This was performed in the same way as other studies $[29,30]$, which demonstrated good homogeneity results when using small sections of the filters.

Table 7 shows the descriptive statistics (number of valid data, mean, standard deviation, minimum, maximum, 5th, and 95th percentiles) for individual $\mathrm{PAH}$ concentrations measured by using the TD-GC/MS method in the city of Bilbao (urban area). PAHs which showed overestimation in the SRM analysis (Naph and Acy) or poor precision in the RRF determination (Ret) were not measured in the real samples.

The average concentration of individual EPA PAHs in Bilbao ranged from $0.04 \pm 0.05$ to $0.50 \pm 0.76 \mathrm{ng} \cdot \mathrm{m}^{-3}$, whereas 
the nonpriority PAHs were between $0.01 \pm 0.01$ and $0.26 \pm$ $0.32 \mathrm{ng} \cdot \mathrm{m}^{-3}$. The EPA PAHs reported minimum values between $4.00 \times 10^{-3}$ and $0.03 \mathrm{ng} \cdot \mathrm{m}^{-3}$ for most of the compounds, which are between 1.1 and 14.6 times the MDL, showing the suitability of the proposed method to determine particle-bound PAHs in real $\mathrm{PM}_{10}$ samples. Although the minimums of IP and DBahA were below their MDL, these values meant only the $5 \%$ or less of the measured samples.

Among compounds, $\mathrm{BbFt}$ was the major contributor to total PAHs (average concentration of $\left.0.5 \pm 0.76 \mathrm{ng} \cdot \mathrm{m}^{-3}\right)$, followed by Pyr $\left(0.27 \pm 0.23 \mathrm{ng} \cdot \mathrm{m}^{-3}\right)$, Ft $\left(0.26 \pm 0.22 \mathrm{ng} \cdot \mathrm{m}^{-3}\right)$, BeP $(0.26 \pm$ $\left.0.32 \mathrm{ng} \cdot \mathrm{m}^{-3}\right)$, and Chry $\left(0.22 \pm 0.24 \mathrm{ng} \cdot \mathrm{m}^{-3}\right)$. The high presence of these compounds in $\mathrm{PM}_{10}$ fraction has been reported by previous studies $[31,32]$ in urban areas with traffic loads.

\section{Conclusions}

The method developed in this study, based on thermal desorption, showed a good efficiency for the determination of particle-bound PAHs. The use of a solvent-free extraction technique has showed numerous advantages (less sample manipulation and analysis time, reduced exposure risk, and higher sensitivity and reliability) that enable a better performance (good recovery, precision, and accuracy) for the determination of particle-bound PAHs; however, the lowest molecular weight PAHs (Naph and Acy) could be overestimated by this methodology.

Parameters such as tube and trap temperature, time, desorption, and split flows (inlet and outlet) were critical in the thermal desorption of PAHs. The optimized TD-GC/MS method showed an efficient desorption of PAHs with recoveries higher than $94 \%$.

The results obtained in the validation of TD-GC/MS by standard reference material (urban dust) demonstrated that this is a reliable method to determine particulate PAHs in aerosol samples (good precision and accuracy), with average recovery efficiency of 96.67 and a mean RSD value of 12.18. Comparing with the conventional method Soxhlet-GC/MS, the TD-CG/MS method demonstrated a better performance for the determination of PAHs. Besides 16 EPA PAHs, the TD-GC/MS method demonstrated its ability to quantify other PAHs in aerosol samples.

Finally, the method was successfully applied for the quantification of PAHs in real $\mathrm{PM}_{10}$ samples collected with a time resolution of $8 \mathrm{~h}$.

\section{Conflicts of Interest}

The authors declare that there are no conflicts of interest regarding the publication of this paper.

\section{Acknowledgments}

The authors gratefully thank the University of the Basque Country UPV/EHU (Ref.: GIU 13/25, GIU 16/03, and UFI 11/47) and the Spanish Ministry of Science and Innovation (MICINN) for financing the project PROMESHAP (Ref.: CTM 2010-20607). Iñaki Elorduy wants to thank the MICINN for his doctoral grant Ministerio de Ciencia e Innovació.

\section{Supplementary Materials}

The representative SCAN chromatograms of the 16 EPAs and deuterated PAHs and also the SIM chromatograms of the target PAHs (16 EPA PAH + 15 PAH) obtained in the SRM 1649b analysis are shown in the supplementary material. Figure S1: chromatogram of 16 EPA and deuterated PAHs in SCAN mode, from 0 to $15 \mathrm{~min}$ : (1) Naph-d8, (2) Naph, (3) Bph-d10, (4) Acy, (5) Ace, and (6) FL. Figure S2: chromatogram of $16 \mathrm{EPA}$ and deuterated PAHs in SCAN mode, from 15 to $20.5 \mathrm{~min}$ : (7) Phe-d10, (8) Phe, (9) Ant, (10) Ft, (11) Pyr-d10, and (12) Pyr. Figure S3: chromatogram of 16 EPA and deuterated PAHs in SCAN mode, from 22.5 to 35.5 min: (13) BaA-d12, (14) BaA, (15) Chry, (16) BbFt, (17) BkFt, (18) BaP-d10, (19) BaP, (20) IP, (21) DBahA, (22) BghiP-d12, and (23) BghiP. Figure S4: PAHs and deuterated PAHs in SIM windows $(\mathrm{m} / \mathrm{z} 226,240,228$, and 234) in the analysis of NIST SRM 1649b dust. Figure S5: PAHs and deuterated PAHs in SIM windows (m/z 252 and 264) in the analysis of NIST SRM 1649b dust. Figure S6: PAHs and deuterated PAHs in SIM windows (m/z 276, 288, and 278) in the analysis of NIST SRM 1649b dust. Figure S7: PAHs and deuterated PAHs in $\mathrm{m} / \mathrm{z} 300$ SIM window in the analysis of NIST SRM 1649b dust. (Supplementary Materials)

\section{References}

[1] R. H. Peng, A. S. Xiong, Y. Xue et al., "Microbial biodegradation of polyaromatic hydrocarbons," FEMS Microbiology Reviews, vol. 32, no. 6, pp. 927-955, 2008.

[2] R. Fernández-González, I. Yebra-Pimentel, E. MartínezCarballo, J. Simal-Gándara, and X. Pontevedra-Pombal, "Atmospheric pollutants in fog and rain events at the northwestern mountains of the Iberian Peninsula," Science of the Total Environment, vol. 497-498, pp. 188-199, 2014.

[3] B. J. Finlayson-Pitts and J. N. Pitts Jr., Chemistry of the Upper and Lower Atmosphere-Theory, Experiments, and Applications, Academic Press, San Diego, CA, USA, 2000.

[4] K. Ravindra, R. Sokhi, and R. V. Vangrieken, "Atmospheric polycyclic aromatic hydrocarbons: source attribution, emission factors and regulation," Atmospheric Environment, vol. 42, no. 13, pp. 2895-2921, 2008.

[5] M. Howsam and K. C. Jones, "Sources of PAHs in the environment," in Anthropogenic Compounds: PAHs and Related Compounds, A. H. Neilson, Ed., pp. 137-174, Springer, Berlin, Germany, 1998.

[6] A. A. Jamhari, M. Sahani, M. T. Latif et al., "Concentration and source identification of polycyclic aromatic hydrocarbons (PAHs) in $\mathrm{PM}_{10}$ of urban, industrial and semiurban areas in Malaysia," Atmospheric Environment, vol. 86, pp. 16-27, 2014.

[7] C. E. Boström, P. Gerde, A. Hanberg et al., "Cancer risk assessment, indicators, and guidelines for polycyclic aromatic hydrocarbons in the ambient air," Environmental Health Perspectives, vol. 110, no. s3, pp. 451-489, 2002.

[8] United Nations Economic Commission for Europe (UNECE), Convention on Longrange Trans-Boundary Air Pollution, United Nations Economic Commission for Europe (UNECE), Aarhus, Denmark, December 2017, http://www.unece.org/ env/lrtap/pops_h1.html.

[9] Council Decision 2004/259/EC of 19 February 2004, Concerning the Conclusion, on Behalf of the European Community, 
of the 1988 Protocol to the 1979 Convention on Long Range Transboundary Air Pollution on Persistent Organic Pollutants [OJ L 81 of 19.03.2004], December 2017, http://eur-lex.europa. eu/legal-content/EN/TXT/?uri=CELEX:32004D0259.

[10] US Environmental Protection Agency, US-EPA, “The U.S. Environmental Protection Agency, list of priority pollutants, Office of water, water quality standards database, Office of the Federal Registration (OFR) appendix A: priority pollutants," Federal Register, vol. 47, p. 52309, 1982.

[11] H. L. Sheu, W. J. Lee, S. J. Lin, G. C. Fang, H. C. Chang, and W. C. You, "Particle-bound PAH content in ambient air," Environmental Pollution, vol. 96, pp. 369-382, 1997.

[12] N.-D. Dat and M. B. Chang, "Review on characteristics of PAHs in atmosphere, anthropogenic sources and control technologies," Science of the Total Environment, vol. 609, pp. 682-693, 2017.

[13] H. Sharma, V. K. Jain, and Z. H. Khan, "Characterization and source identification of polycyclic aromatic hydrocarbons (PAHs) in the urban environment of Delhi," Chemosphere, vol. 66, no. 2, pp. 302-310, 2007.

[14] K. Srogi, "Monitoring of environmental exposure to polycyclic aromatic hydrocarbons: a review," Environmental Chemistry Letters, vol. 5, no. 4, pp. 169-195, 2007.

[15] M. Tsapakis and E. G. Stephanou, "Occurrence of gaseous and particulate polycyclic aromatic hydrocarbons in the urban atmosphere: Study of sources and ambient temperature effect on the gas/particle concentration and distribution," Environmental Pollution, vol. 133, no. 1, pp. 147-156, 2005.

[16] A. Lottmann, E. Cadé, M. L. Geagea et al., "Separation of molecular tracers sorbed onto atmospheric particulate matter by flash chromatography," Analytical Bioanalytical Chemistry, vol. 387, no. 5, pp. 1855-1861, 2007.

[17] S. Chantara and W. Sangchan, "Sensitive analytical method for particle-bound polycyclic aromatic hydrocarbons: a case study in Chiang Mai, Thailand," ScienceAsia, vol. 35, pp. 42-48, 2009.

[18] D. L. Poster, M. M. Schantz, L. C. Sander, and S. A. Wise, "Analysis of polycyclic aromatic hydrocarbons (PAHs) in environmental samples: a critical review of gas chromatographic (GC) methods," Analytical and Bioanalytical Chemistry, vol. 386, no. 4, pp. 859-881, 2006.

[19] L. B. Liu, Y. Liu, J. M. Lin, N. Tang, K. Hayakawa, and T. Maeda, "Development of analytical methods for polycyclic aromatic hydrocarbons (PAHs) in airborne particulates: a review," Journal of Environmental Sciences, vol. 19, no. 1, pp. 1-11, 2007.

[20] M. S. Alam, I. J. Keyte, J. Yin, C. Stark, A. M. Jones, and R. M. Harrison, "Diurnal variability of polycyclic aromatic compound (PAC) concentrations: relationship with meteorological conditions and inferred sources," Atmospheric Environment, vol. 122, pp. 427-438, 2015.

[21] J. Ringuet, A. Albinet, E. Leoz-Garziandia, H. Budzinski, and E. Villenave, "Diurnal/nocturnal concentrations and sources of particulate-bound PAHs, OPAHs and NPAHs at traffic and suburban sites in the region of Paris (France)," Science of the Total Environment, vol. 437, pp. 297-305, 2012.

[22] S. K. Pandey, K. H. Kim, and R. J. C. Brown, "A review of techniques for the determination of polycyclic aromatic hydrocarbons in air," TrAC Trends in Analytical Chemistry, vol. 30, no. 11, pp. 1716-1739, 2011.

[23] J. E. Szulejko, K.-H. Kim, R. J. Brown, and M.-S. Bae, "Review of progress in solvent-extraction techniques for the determination of polyaromatic hydrocarbons as airborne pollutants," TrAC Trends in Analytical Chemistry, vol. 61, pp. 40-48, 2014.

[24] S. Elcoroaristizabal, A. de Juan, J. A. García, I. Elorduy, N. Durana, and L. Alonso, "Chemometric determination of
PAHs in aerosol samples by fluorescence spectroscopy and second-order data analysis algorithms," Journal of Chemometrics, vol. 28, no. 4, pp. 260-271, 2014.

[25] ISO, International Standard ISO 12884-Ambient airDetermination of Total (gas and particle-phase) PAHs: Collection on Sorbent-Backed Filters with GC/MS Analyses, ISO, Geneva, Switzerland, 2000.

[26] PerkinElmer, TurboMatrix Series Thermal Desorbers: User's Guide, PerkinElmer, Inc., UK, 2007.

[27] L. R. Bordajandi, M. Dabrio, F. Ulberth, and H. Emons, "Optimisation of the GC-MS conditions for the determination of the $15 \mathrm{EU}$ foodstuff priority polycyclic aromatic hydrocarbons," Journal of Separation Science, vol. 31, no. 10, pp. 1769-1778, 2008.

[28] I. Elorduy, S. Elcoroaristizabal, N. Durana, J. A. García, and L. Alonso, "Diurnal variation of particle-bound PAHs in an urban area of Spain using TD-GC/MS: influence of meteorological parameters and emission sources," Atmospheric Environment, vol. 138, pp. 87-98, 2016.

[29] J. Ringuet, A. Albinet, E. Leoz-Garziandia, H. Budzinski, and E. Villenave, "Reactivity of polycyclic aromatic compounds (PAHs, NPAHs and OPAHs) adsorbed on natural aerosol particles exposed to atmospheric oxidants," Atmospheric Environment, vol. 61, pp. 15-22, 2012.

[30] E. Grandesso, P. Pérez Ballesta, and K. Kowalewski, "Thermal desorption GC-MS as a tool to provide PAH certified standard reference material on particulate matter quartz filters," Talanta, vol. 105, pp. 101-108, 2013.

[31] J. Aldabe, C. Santamaría, D. Elustondo et al., "Polycyclic aromatic hydrocarbons (PAHs) sampled in aerosol at different sites of the western Pyrenees in Navarra (Spain)," Environmental Engineering Management Journal, vol. 11, pp. 1049-1058, 2012.

[32] M. S. Callén, J. M. López, A. Iturmendi, and A. M. Mastral, "Nature and sources of particle associated polycyclic aromatic hydrocarbons $(\mathrm{PAH})$ in the atmospheric environment of an urban area," Environmental Pollution, vol. 183, pp. 166-174, 2013. 

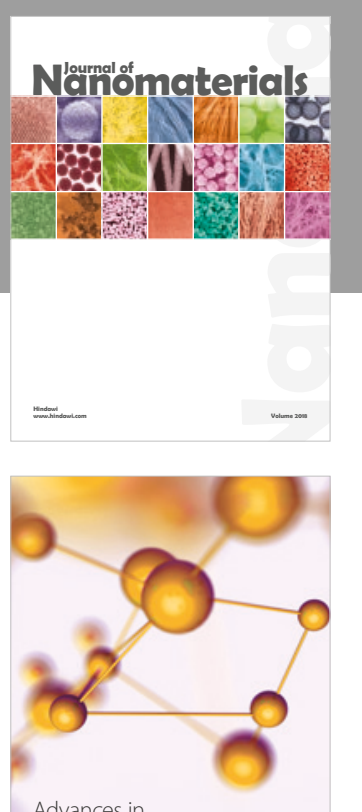

Physical Chemistry
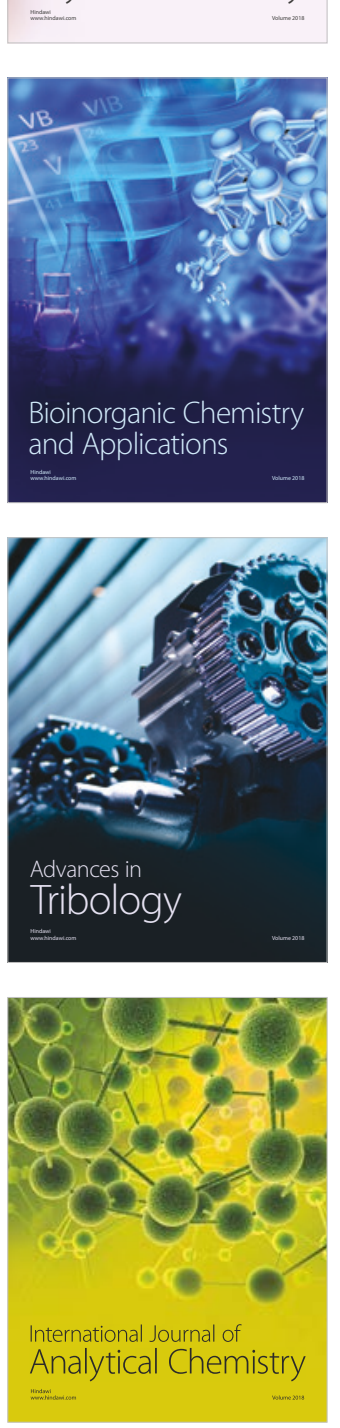

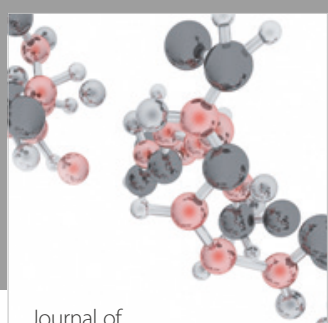

Analytical Methods

in Chemistry

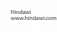

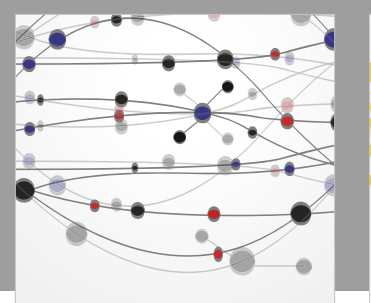

The Scientific World Journal

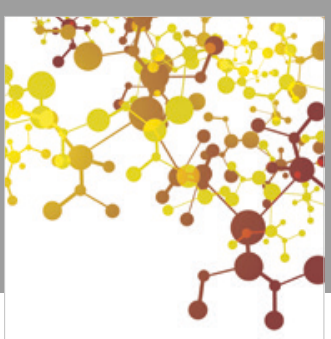

Journal of

Applied Chemistry
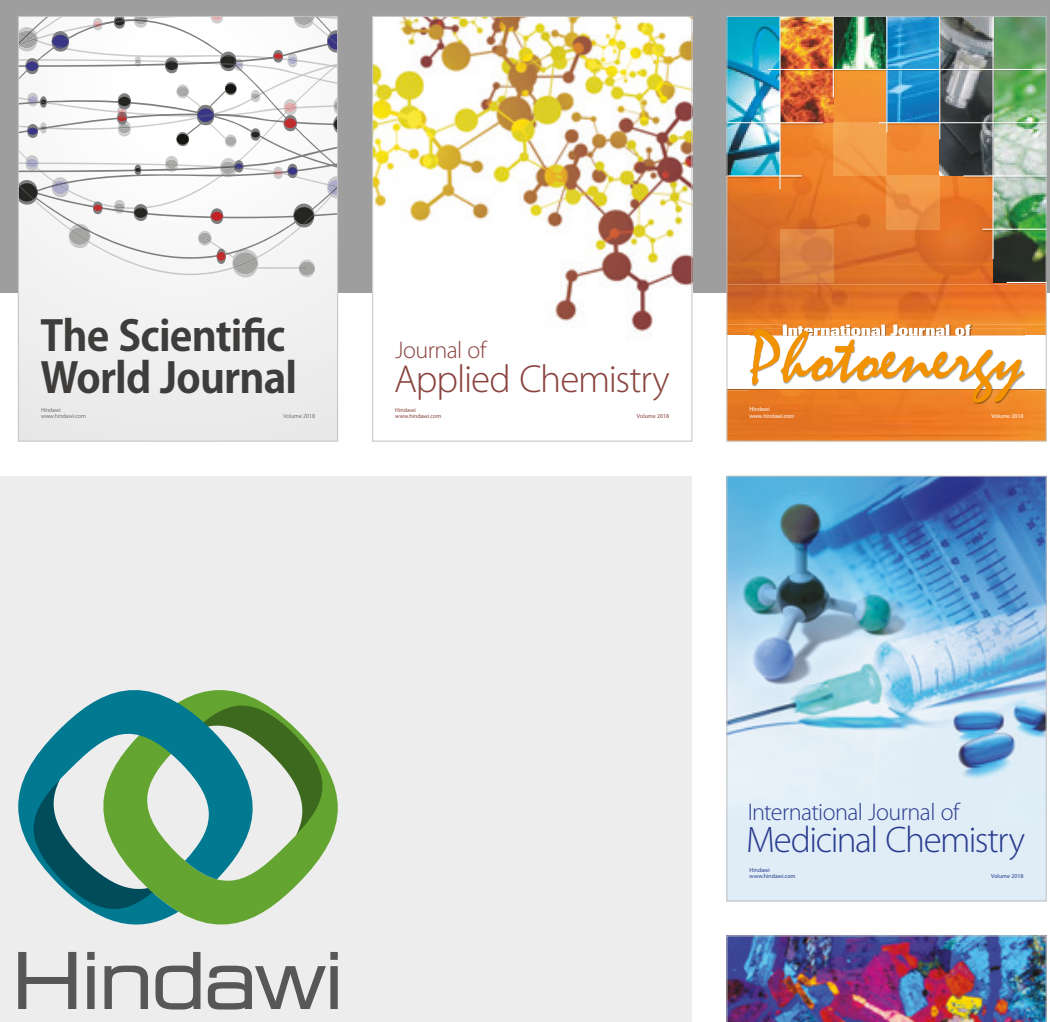

Submit your manuscripts at

www.hindawi.com
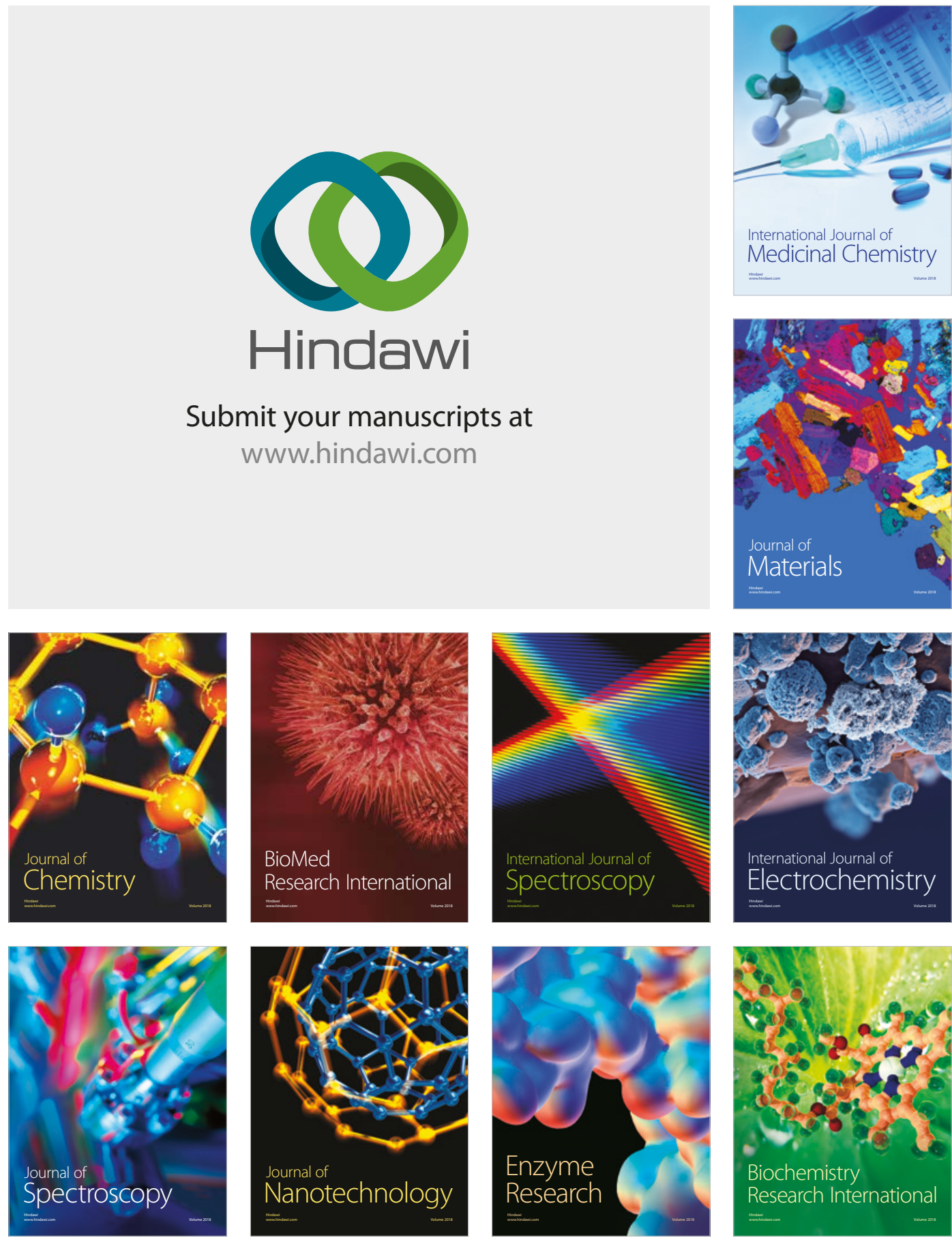
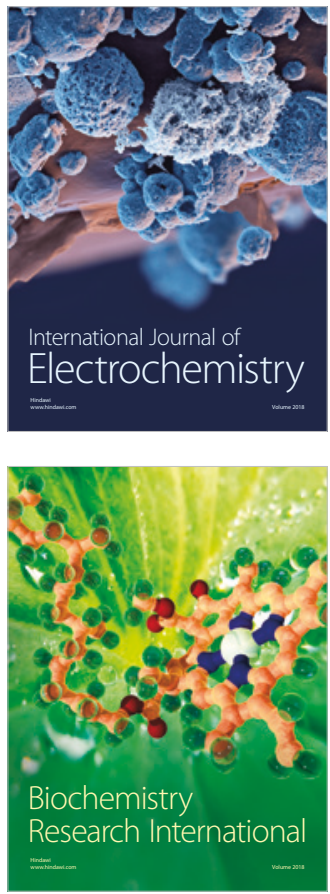